\title{
Medical Image of the Week: Cervical Fracture and Dislocation
}

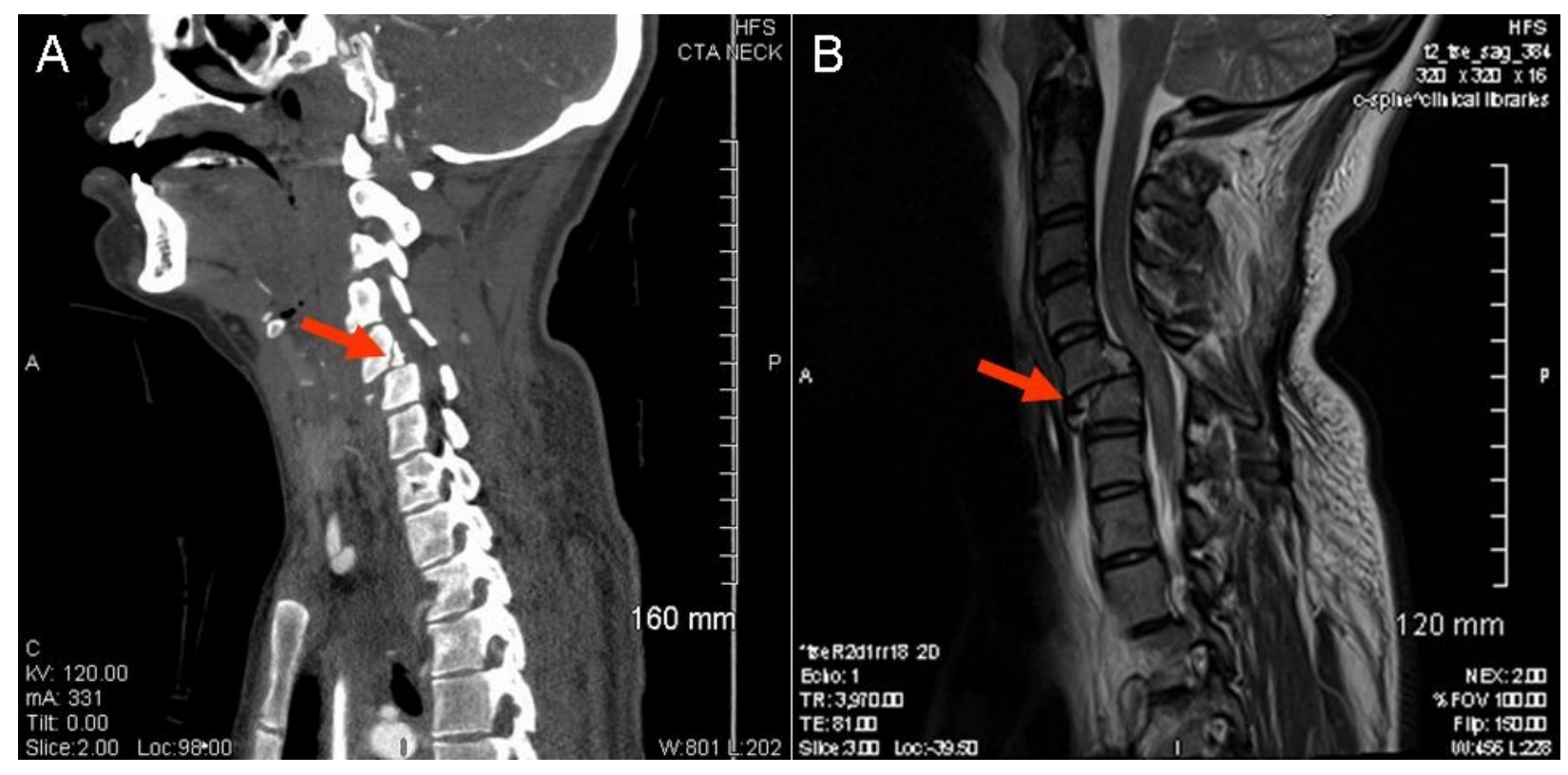

Figure 1. Panel A: Computerized tomography (CT) scan of the neck showing C5-C6 fracture and dislocation (arrow). Panel B: Accompanying magnetic resonance imaging (MRI) of the neck.

A 25 year old woman was a restrained driver in a rollover motor vehicle accident (MVA) and suffered a C5-C6 fracture-dislocation with spinal cord injury (Figure 1). She developed neurogenic stunned myocardium, symptomatic bradycardia and neurogenic shock. Her cardiac ultrasound has been previously presented and can be viewed by clicking here. After developing the adult respiratory distress syndrome and multi-system organ failure she had multiple cardiac arrests and died after 5 days in the intensive care unit.

Evan D. Schmitz, MD

Richland, Washington 